\title{
POTASSIUM DEFICIENCY AND THE ROLE OF THE KIDNEY IN ITS PRODUCTION 1, 2
}

\author{
By ROBERT TARAIL 3 AND J. RUSSELL ELKINTON * \\ (From the Department of Internal Medicine, Yale University School of Medicine, New Haven)
}

(Received for publication June 24, 1948)

It has been recognized that a depression of the concentration of potassium in serum may reflect a concomitant deficiency of potassium in the cells of the body (1). Low concentrations of potassium in serum and diminished potassium contents of skeletal muscle have been reported in experimental animals maintained on diets deficient in potassium (2) and in animals treated with large doses of desoxycorticosterone (3). Depressions of the concentration of potassium in serum have been observed clinically in patients receiving desoxycorticosterone (4), in familial periodic paralysis (5, $6)$, in diabetic acidosis $(7,8)$, in intestinal obstruction (9), and in diarrhea (10). In some of these conditions deficit of cellular potassium has been indicated by negative balances of potassium when the intake of potassium was low and retention of potassium when the ion was administered (10-13). However, significant alterations in the cellular content of potassium may occur without much change in the amount and concentration of potassium in the extracellular fluid and serum $(10,14)$. Levels of serum potassium therefore, may, but do not necessarily, reflect the state of depletion or repletion of cellular potassium.

The study reported here was undertaken in an attempt to elucidate some of the clinical problems of potassium deficiency in adult patients. These problems include the relation of the concentration of potassium in serum to cellular deficiency of the ion, the extent of such cellular deficiencies and their relation to retention of administered potassium, and the physiological abnormalities by which such deficits are produced.

1 Aided by a grant from the James Hudson Brown Memorial Fund of the Yale University School of Medicine.

2 Read in abstract form before the annual meeting of the American Society for Clinical Investigation, Atlantic City, May 3, 1948.

${ }^{8}$ Life Insurance Medical Research Fellow.

4 Present address: Department of Medicine, Hospital of the University of Pennsylvania, Philadelphia.

\section{EXPERIMENTAL MATERIAL AND PROCEDURE}

Six adult patients on the medical and surgical services of the New Haven Hospital were studied. Of these, five were suffering from conditions involving extensive losses of fluids from the gastrointestinal tract, and the sixth had a cerebral vascular disturbance with quadriplegia. All the patients were being sustained wholly or in part by parenteral fluids with minimal amounts of potassium. Four of the patients with gastrointestinal fluid loss had abnormally low concentrations of potassium in serum.

In all patients exchanges of chloride, sodium, potassium and nitrogen were measured during a series of periods of 24 hours or longer. In five of the patients these measurements were made in one or more preliminary periods during which a negligible amount of potassium was given. These were followed by periods of potassium administration. In Case 1, A. M., potassium was given in the initial period. In five cases the potassium was given parenterally as $\mathrm{K}_{2} \mathrm{HPO}_{4}$ and $\mathrm{KH}_{2} \mathrm{PO}$, in molar ratio of 3.55 to 1 to yield a $\mathrm{pH}$ of 7.35 ; in the sixth case it was given as $\mathrm{KCl}$. These potassium salts, added to the other intravenous fluids in concentrations up to 70 m.eq. per liter, were given slowly at a rate not in excess of $20 \mathrm{~m}$.eq. per hour. The amount of potassium given by the intravenous route varied from 29 to 167 m.eq. per day. Water and sodium chloride were administered according to the clinician's opinion of the various requirements of the moment; before potassium therapy was instituted, two of the patients were maintained on intakes high in sodium (J. L., E. R.), and four on intakes low in sodium in varying degrees. All of the patients were given carbohydrate and casein hydrolysate during most of the periods. Clinical diagnoses are appended to Table I.

Two normal control subjects were maintained for three successive 24-hour periods on a liquid diet of milk fortified with "Dextri-Maltose." This diet was isocaloric with the usual daily intake of the subjects and kept them approximately in nitrogen equilibrium. On the second of the three days, 10 grams of $\mathrm{KCl}$ were added to the diet to ascertain whether retention of potassium could be induced under these circumstances in a normal subject during a 24-hour period or longer.

One normal control subject was also given an isocaloric diet low in potassium for two 24-hour periods. The diet consisted of a solution of casein, lactose, butter and sodium chloride. The experiment was designed to determine the minimal rate of renal excretion of potas- 


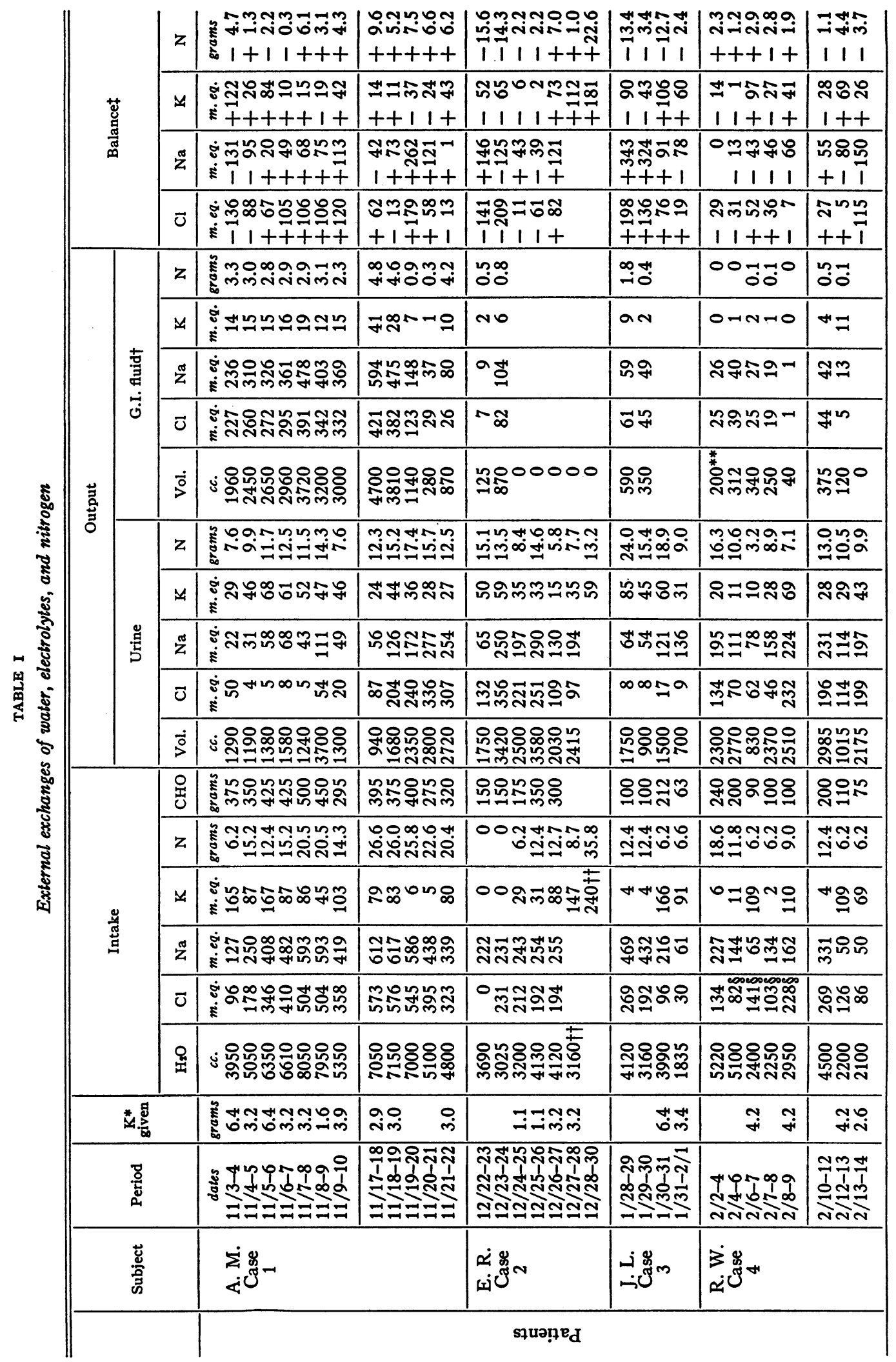




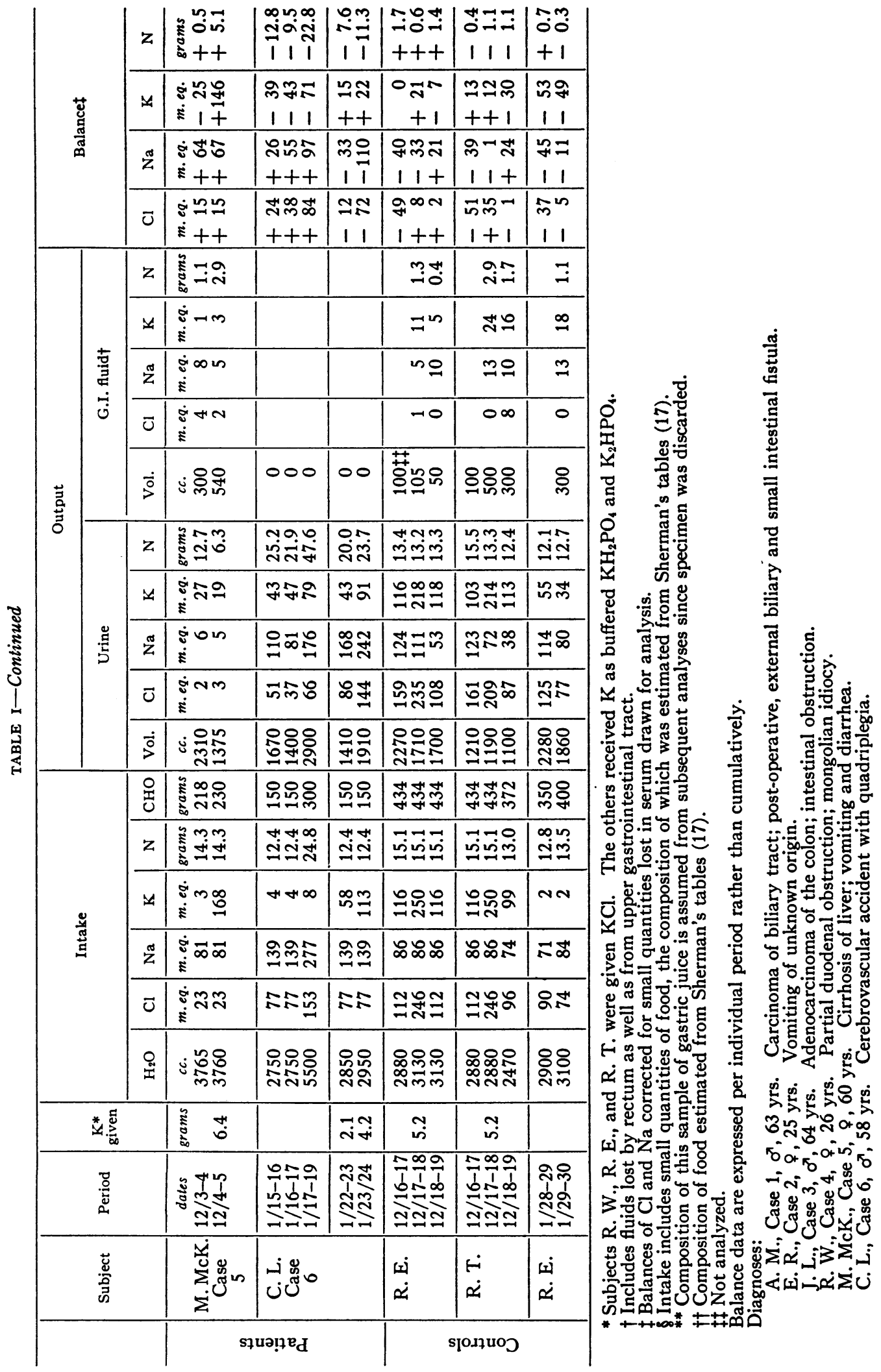




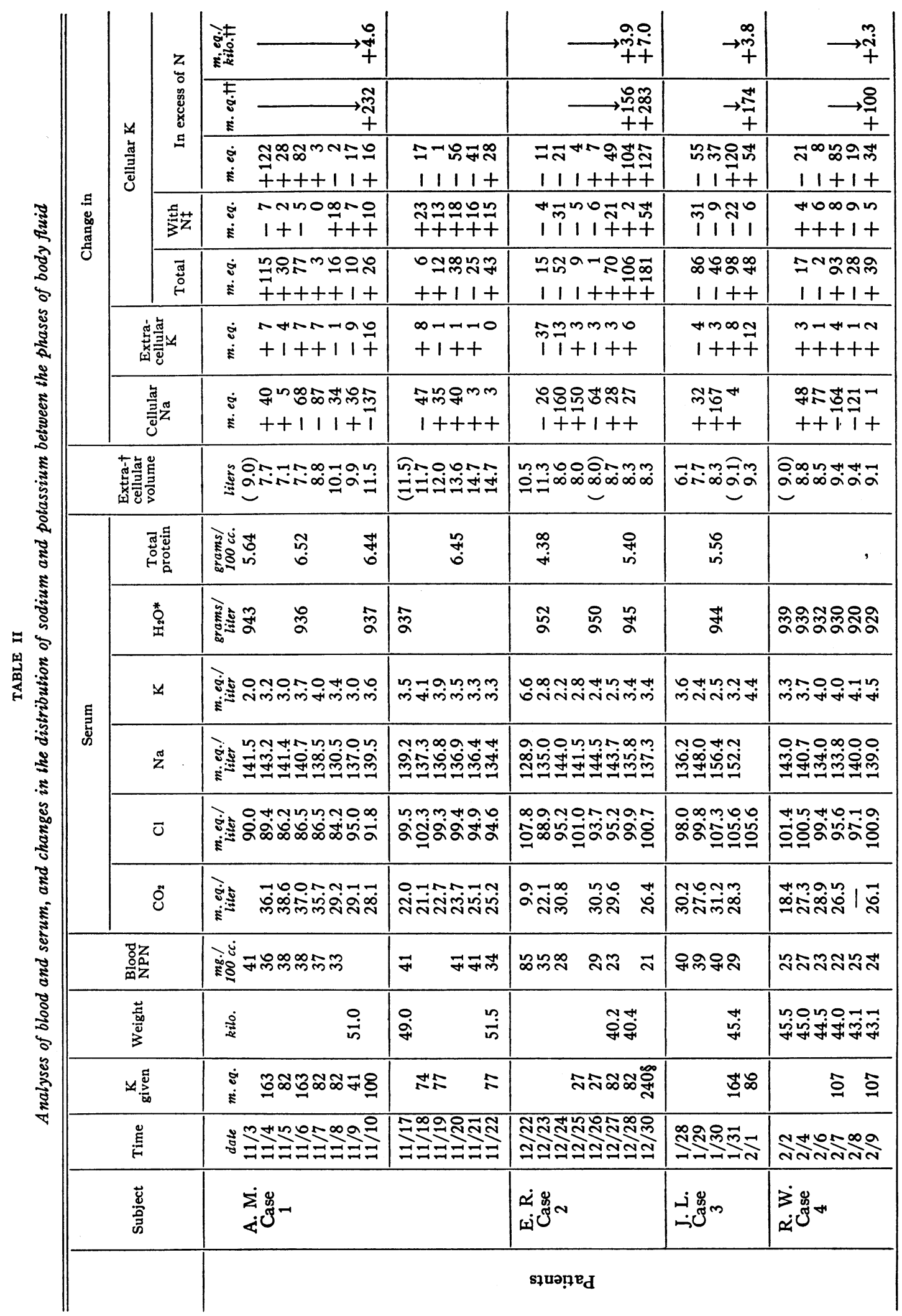




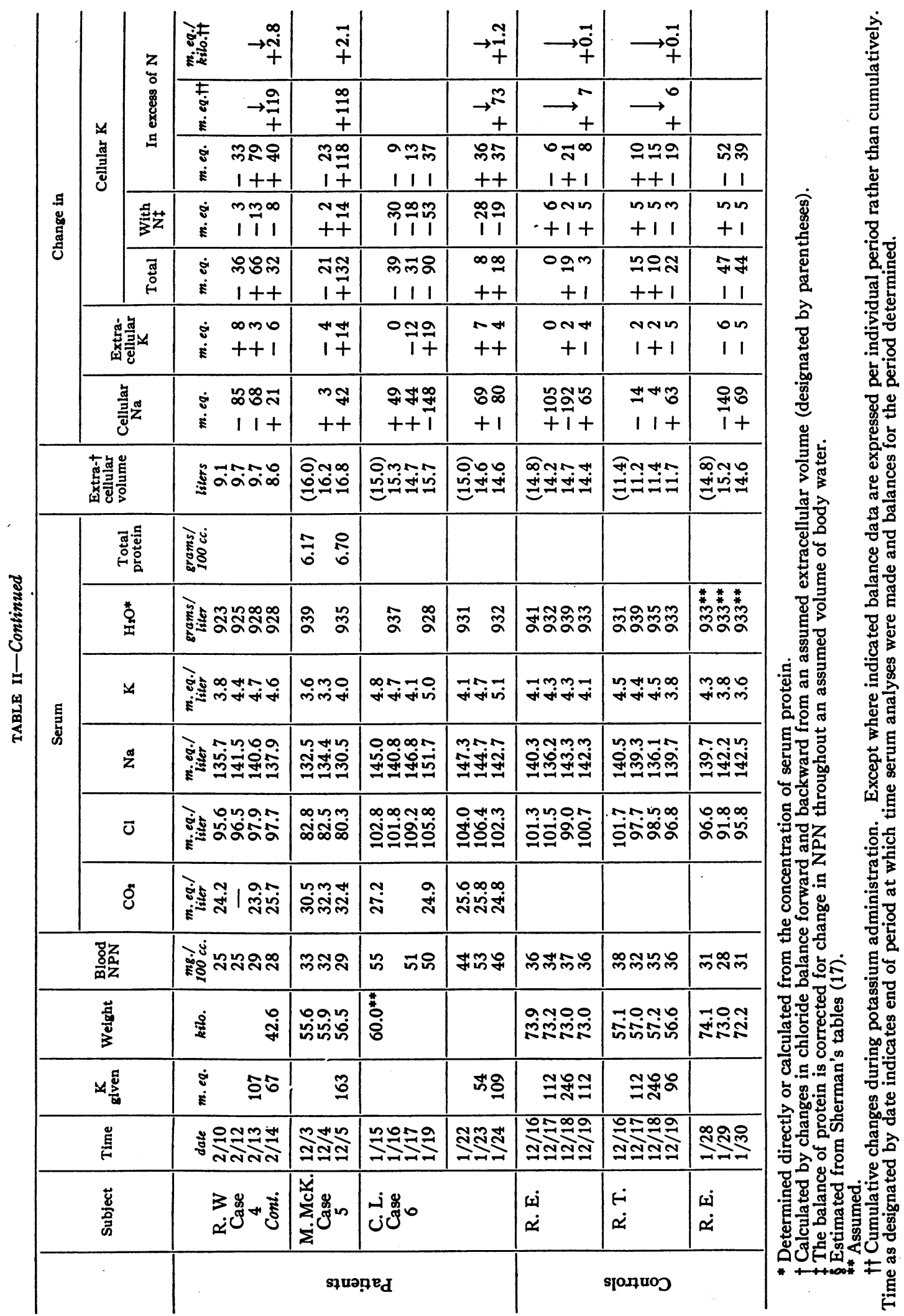


sium in a subject in nitrogen equilibrium and not initially depleted of potassium.

\section{METHODS}

The amounts of potassium and sodium in serum, urine, and other body fluids were measured with the flame photometer (15). The other chemical methods which were used, and the methods of calculation of the derived data, have been previously reported $(14,16)$. In the present study the concentration of potassium in extracellular fluid was assumed to be the same as that in serum because of the uncertainty concerning the proportion of the latter which is non-diffusible. Any error in this assumption would have little effect on the calculated transfers of intracellular potassium. In order to differentiate at least to some extent between transfers of potassium which are associated with cellular anabolism or catabolism and those which are not, a relationship of potassium to nitrogen must be assumed. In the former studies just cited a ratio was used of potassium to nitrogen of $2.4 \mathrm{~m} . e q$. to $1 \mathrm{gram}$; the same ratio has been employed in the present calculations to determine the movements of potassium in "excess" of nitrogen. Use of the $\mathrm{K}: \mathrm{N}$ ratio of $3: 1$ as advocated by Darrow (10) and which probably represents the upper limit of this ratio, would increase the magnitude of the change in cell potassium associated with nitrogen by 20 per cent, but would not significantly alter the direction of change of excess cell potassium or the conclusions based thereon.

\section{RESULTS}

The analytical and derived data are presented in Tables I and II and in Figures 1 to 6.

The patients retained a significant portion of administered potassium in the cellular phase in ex-

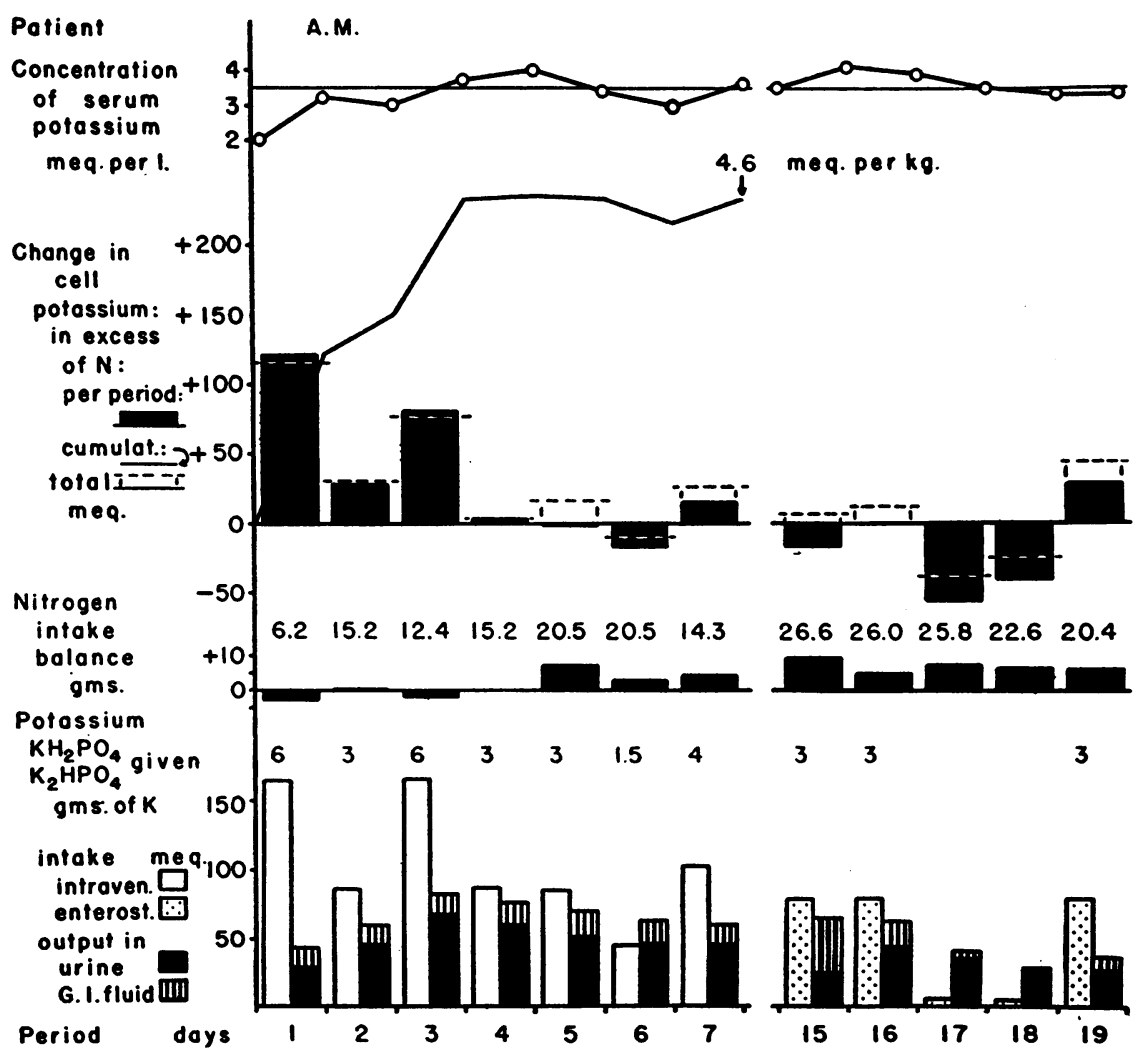

Fig. 1. Exchanges of Potassium and Nitrogen in a Patient Treated with Potassium Phosphate

Two periods are shown of potassium administration to a patient (A. M., Case 1) with a duodeno-biliary external fistula who received nothing by mouth for 34 days. On Days 1 to 7 inclusive, potassium phosphate was given by vein, on Days 15, 16, and 19 by enterostomy.

Potassium retention in the cellular phase was maximal during the first three days; little was retained thereafter. When potassium was stopped during Days 17 and 18 urinary excretion of potassium persisted. Except for one 24-hour period, more potassium was invariably excreted in urine than in gastrointestinal fluid. 


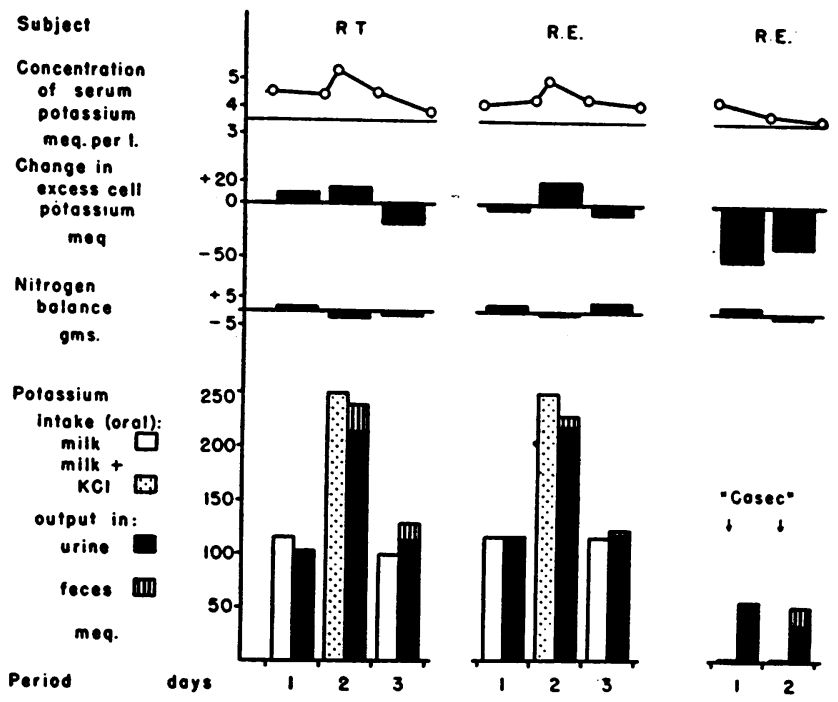

Fig. 2. Exchanges of Potassium in Two Control Normal SubJects on High and Low Intakes of the Ion

In all three experiments the subjects were on isocaloric diets. In the first two experiments the moderate oral intake of potassium in milk was supplemented on Day 2 with $\mathrm{KCl}$. No significant amounts of potassium were retained. In the third experiment, despite the low intake, potassium continued to be excreted in the urine and a cellular deficit was initiated.

cess of nitrogen. As the control subjects did not, this retention presumably indicates a pre-existing cellular deficit of the ion. The magnitude of the deficit was not defined by the extent of retention in each patient, however, since only in Case 1, A. M., was potassium administered for a sufficient length of time to demonstrate that the patient's cells were approaching saturation (Figure 1); the other patients were still retaining potassium at the end of the study. The amount of potassium so retained ranged between 73 and 232 m.eq., or 1.2 to 4.6 m.eq. per kilogram of body weight (Table II). The upper limit of this range would be increased to 283 m.eq., or 7.0 m.eq. per kilogram, if the last two days of Case 2, E. R., are included when the intake of potassium in food was calculated from Sherman's tables (17). The two normal subjects who were given somewhat larger quantities of potassium, retained $0.1 \mathrm{~m}$. eq. per kilogram each over the three 24-hour periods; essentially all of the potassium given was excreted (Table II, Figure 2).

The cellular deficits of potassium as demonstrated by retention of the ion were usually, but not always, associated with a low concentration of serum potassium; when the concentration of potassium in the serum was low a cellular deficit was always present (Figure 3, [a]). When the cellular content of potassium was increased, both the serum concentration and the absolute amount of extracellular potassium tended to rise; but considerable alteration occurred in the former fraction of potassium with relatively minor changes in the latter two values (Figure 3, [b and c]).

The major factor in the development of deficits of potassium in these patients appeared to be the continued excretion of potassium by the kidney during times of restricted ingestion of the ion. Since these patients were not studied quantitatively from the time of onset of their disease, the data do not contain complete evidence concerning the mode of origin of the potassium deficits. Loss of potassium by vomiting and diarrhea must have been a contributory factor. In Cases 1 to 5 fluid had been lost steadily from stomach or upper small intestine for periods of four days to three months, immediately preceding the studies. Direct analyses of samples of such fluids in four of these cases revealed potassium concentrations one to six times as high as those of normal serum, and losses of as 


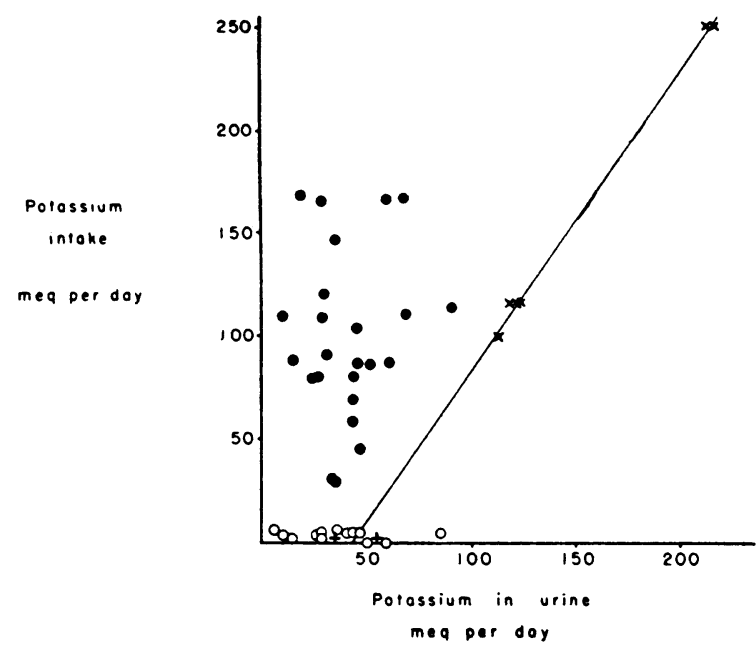

Fig. 4. Relation of the Daily Excretion of PotasSiUM in URine to the DaIly Intake of Potassium

Data are for 24-hour periods, crosses represent periods of low $(t)$ and high $(x)$ intake of potassium in the normal subjects. Open and solid circles represent similar periods, respectively, in the patients.

Potassium excretion varied directly with the intake of the ion in the normal subjects but not in the patients. In both groups, the excretion of potassium persisted when the intake was negligible.

large increases in the renal excretion of the ion. The concentration of serum potassium was measured at intervals of 24 hours; levels at intermediate points closer to the actual time of potassium administration were probably higher, at least in the normal subjects. Failure of the serum concentra-

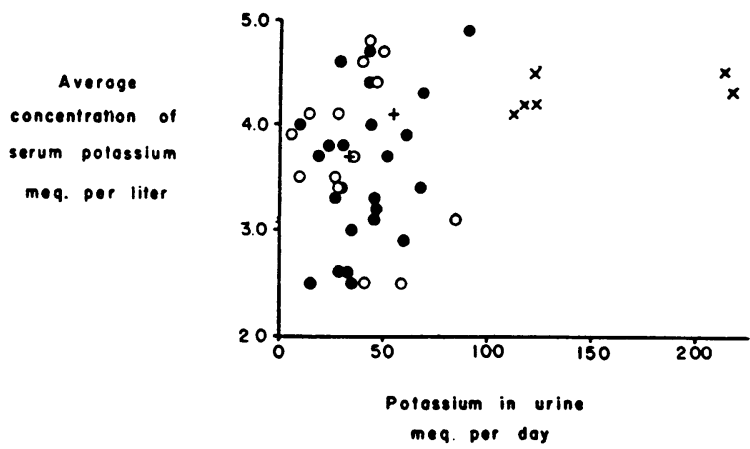

Fig. 5. Relation of the Daily Excretion of Potassium in Urine to the Average Concentration of Potassium In Serum

Symbols are the same as in Figure 4. In the normal subjects, slight increases in serum concentration were associated with large increases in the rate of excretion of potassium. This relationship did not hold in the patients. tion to rise to comparable intermediate levels might explain the failure of the patients to excrete as much potassium as did the controls. In the former the amount of potassium excreted in the urine bore no relation to the amount of potassium given (Figure 4). In four of the patients actually less potassium was excreted during periods of high intake than during those of low intake. Unfortunately our data cannot define completely the role of the serum potassium level in this phenomenon, but presumably the primary cause for the failure of the patients to excrete administered potassium was the avidity of the cells of other tissues for the ion.

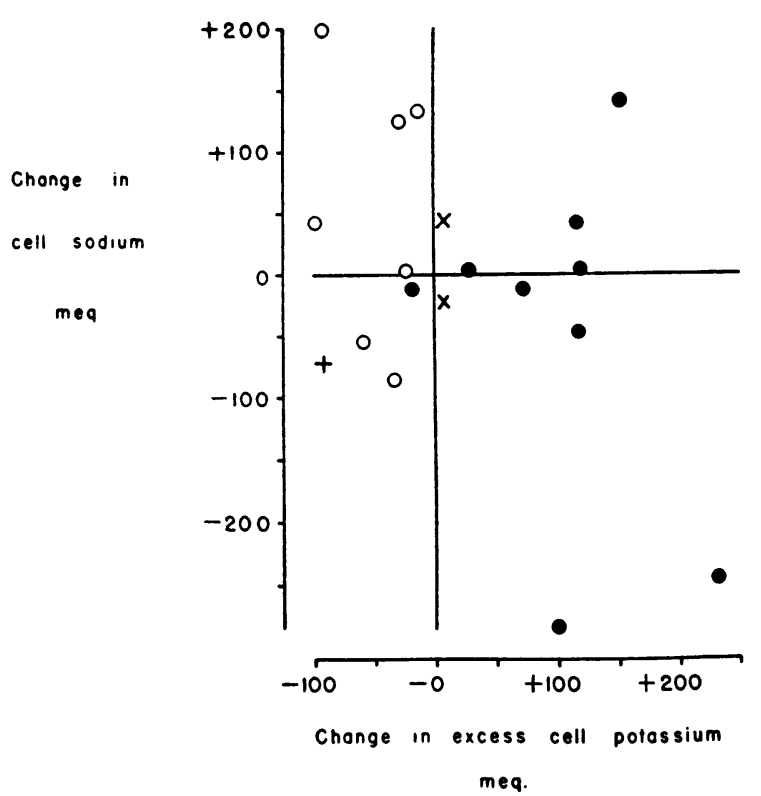

Fig. 6. Comparison of Changes in Excess Cell Potassium and in Cell Sodium

Symbols are the same as in Figure 3, except that the summation of periods in Case 4, R.W., is omitted. An inverse relationship is present in only a few of the periods,

Disturbances in the distribution of other electrolytes could not be causally related to the potassium deficiencies in our patients. There was no consistent relationship between the concentrations in the serum of sodium or chloride and those of potassium (Table II). An inverse relationship between changes in cell sodium and changes in cell potassium was present in only a few of the patients (Figure 6). The $\mathrm{CO}_{2}$ content of serum was abnormally high at some stage in the course 
of these studies in four of the six patients, but only in Case 1 was it clearly unrelated to the intravenous infusion of alkali or to a possible primary $\mathrm{CO}_{2}$ excess (Table II). The administration and retention of potassium did not appear to alter significantly the nitrogen balance. Only in two cases (Cases 3 and 5) did the latter become less negative or more positive when potassium was given while the nitrogen intake was maintained at the same level (Table I).

Electrocardiographic and clinical findings in these patients were surprisingly non-specific with respect to potassium deficiency. In the patients with low concentrations of serum potassium, electrocardiographic abnormalities, e.g., depression of the $\mathrm{T}$ waves, were noted which were similar to those previously reported $(18,19)$. There was no precise correlation between the level of serum potassium and the degree of electrocardiographic disturbance. During the course of infusions of potassium these abnormalities sometimes receded but no cardiotoxic effects supervened. No definite symptoms or physical signs of neuromuscular disturbance, respiratory embarrassment, or specific cardiac abnormality were observed, despite the fact that four of the patients had concentrations of serum potassium in the range of those reported in familial periodic paralysis (5) and in other patients in whom paralytic phenomena were attributed to hypokaliemia $(7,20,21)$. No detrimental effects of potassium administration were seen with the following exceptions : in Case 1 more fluid was lost through the rectum when potassium phosphate was added to the fluid given through the enterostomy, and diarrhea occurred in one of the normal subjects following the ingestion of potassium chloride. Otherwise, the patients tolerated the potassium therapy well.

\section{DISCUSSION}

Limits and sources of error. The magnitude of changes observed in these studies greatly exceeded any possible sources of errors in chemical determinations. This was also true with respect to the collection of specimens despite the fact that the patients were studied on the open ward. Electrolyte losses in sweat were not measured. As the patients were not sweating profusely, this neglect as far as potassium is concerned would be of minor importance $(22)$; in the case of chloride and so- dium, the error might be greater, but probably would not significantly alter results.

The derived data were calculated on the basis of certain assumptions which are open to question. Changes in extracellular potassium were estimated from alterations in the chloride space. Admittedly some chloride is intracellular but its magnitude is small. In addition the extracellular potassium is a relatively minor fraction of total body potassium. The questionable validity of equating the chloride space with the extracellular fluid, therefore, does not invalidate the derived data on exchanges of cellular potassium. But the relatively large extracellular component of sodium does mean that the estimated changes in cellular sodium are only rough approximations.

A relationship of potassium to nitrogen has been assumed in order to calculate which transfers of cellular potassium were due to tissue anabolism or catabolism, and which were occurring in intact tissue cells. Such $\mathrm{K}: \mathrm{N}$ ratios as have been used for this purpose have been derived either from tissue (skeletal muscle) analyses or from the excretion of these substances by fasting subjects $(16,23)$. It is possible that this relationship may vary widely in other circumstances $(24,25,26)$. But the $\mathrm{K}: \mathrm{N}$ ratio was used as the only available yardstick to permit at least some differentiation between these two types of transfers of cellular potassium. In any case the uncorrected change in cellular potassium was in the same direction as significant changes in excess potassium in all the subjects studied, and the correction for potassium associated with nitrogen was small in most instances.

Relation of retention of potassium to deficit of the ion. The two control studies indicate that extra potassium given to a normal subject is not retained. Similar evidence has been found in previous investigations for both shorter and longer periods of time (27 to 30 ). Since the potassium was administered to both the patients and the control subjects in comparable amounts, and over a comparable period of time, there appears to be some justification in equating retention of the ion with a pre-existing deficit.

The patients retained 1.2 to 7.0 m.eq. of excess cell potassium per kilogram. Darrow's infants with diarrhea retained 5.8 to 17.3 m.eq. per kilogram (10). However, the estimation of a deficit by the retention of an administered substance re- 
quires saturation of the subject; i.e., it must be given until no more is taken up by the cells. Since only one patient, Case 1, (A. M.), was so saturated, the positive balances of potassium exhibited by the other patients probably did not measure the full extent of their potassium deficits.

Mechanism of potassium depletion. During the periods of study our patients lost smaller quantities of potassium in gastrointestinal fluids than in urine, although larger quantities may have been lost via the gastrointestinal tract during the periods preceding the studies. Undoubtedly this latter route of loss may be of greater importance in many cases of diarrhea (10), steatorrhea (12), and vomiting (9). But in the cases presented here, a low intake of potassium in conjunction with the continued excretion of the ion in the urine was an important, if not the principal, factor in producing the cellular deficit.

Excretion of potassium in excess of nitrogen and negative balances of potassium are familiar phenomena in a variety of physiological disturbances. These have been observed in diverse groups of patients maintained on the usual varieties of parenteral fluids and may be accelerated during post-operative periods as part of an injury reaction (31 to 34$)$; they occur during starvation (23) and dehydration (16). The nature of these disturbances suggests that processes of cellular metabolism play an important role in determining the total exchanges of potassium. Our data, however, emphasize the importance of the renal excretion of the ion.

The continued renal excretion of potassium by our patients during periods of low potassium intake does not indicate abnormal renal function, but rather normal function of the kidneys under abnormal circumstances. With one possible exception there was no evidence that any of these patients had diseased kidneys. Their rates of potassium excretion were quite comparable with that of the control subject (R. E.) on a low potassium diet. Furthermore, most patients with severe renal disease have a lower rather than a higher rate of excretion of the ion (35). It is necessary, therefore, to consider the ways in which the abnormal conditions influence the excretion of potassium by the normal kidney.

Winkler and others have demonstrated that under normal conditions increases in the intake of potassium and in its concentration in serum are associated with increases in the rate of excretion of potassium $(27,28,36)$. These findings are confirmed in the control experiments reported here in that large increments of potassium in the urine occurred with slight rises in the serum concentrations. Intermediate analyses of the serum level might have revealed higher concentrations. In the patients during periods of cellular depletion of the ion no positive correlation was apparent between intake of potassium or its concentrations in serum and the daily output of potassium. Rapid uptake of potassium by the cells may have prevented comparable intermediate rises in serum concentrations thus explaining the failure of the kidney to excrete it. But such a simple explanation can hardly account for the fact that in some instances the rate of excretion of potassium was actually lower during periods of administration when the average serum level was normal, than during periods when intake and 'serum concentration were low. The administration of potassium appeared to shift the equilibria of potassium transfers in the various phases of body fluid from the direction of excretion in the kidneys to movement into tissue cells.

Potassium has been regarded as a "threshold" substance (37). Concentrations of urine potassium below 4 m.eq. per liter have been recorded during diuresis and potassium depletion $(11,28$, 38,39 ). Concomitant serum concentrations in one study were not greater than those in urine, and in the other studies no concomitant serum concentrations of potassium were reported. In our patients the concentration of potassium was never lower in urine than in serum. Considering renal tubular function as a whole and assuming that the tubular cells are surrounded by the usual type of extracellular fluid, no evidence has been found that potassium can be reabsorbed against a concentration gradient. This does not exclude the possibility that such reabsorption may occur in a given portion of the renal tubule.

Relation of transfers of cellular potassium to those of other ions. Aside from the renal excretion of potassium, it is pertinent to inquire into the relation of transfers of cellular potassium to the exchanges of other extracellular and intracellular ions.

The data confirm previous studies in this laboratory and elsewhere (14) in showing that large 
amounts of potassium may enter or leave the intracellular fluid with relatively small increments or decrements of the extracellular fraction of the ion. Some changes in concentration of extracellular potassium may take place. The data show that an abnormally low concentration was always associated with a cellular deficit of the ion. But the converse was not true; one patient, Case 4, (R. W.), had a normal concentration, and one, Case 2, (E. R.), had an elevated concentration of potassium in serum. This is consistent with other investigations in which the evidence suggests that cellular deficiency of potassium may co-exist with normal or elevated concentrations of the ion in the extracellular phase $(10,33,34)$. As many patients are suffering from salt loss, dehydration, peripheral vascular collapse and oliguria, it has been suggested that this phenomenon is the result of impairment of renal function. This did not appear to be the fact in Case 4, R. W., but might well explain the high serum concentration observed in Case 2, E. R. This apparent paradox must be kept in mind during any attempt to assess the potassium requirement of the patient.

Under certain circumstances a close relationship has been noted between potassium depletion and alkalosis due to excess of bicarbonate in the extracellular fluid. In four of our six patients the concentration of serum bicarbonate was elevated to some extent before potassium therapy and fell to within normal limits after administration of the ion. Darrow postulated that such a relationship holds only under certain conditions, viz., deficit of only one ion (e.g. potassium), and attainment of a state of equilibrum by adequate renal function (40). All of our cases were studied for periods of 24 hours or longer during which renal function was adequate, but electrolyte deficits were not restricted to only one ion. It is interesting, therefore, that our data fit in as well as they do with Darrow's findings.

One other observation is noteworthy: the elevated serum bicarbonate concentration in Case 1 , A. M., did not return to normal after the deficit of cell potassium had been corrected during four days of treatment, but did return to normal three days later when the equivalent amount of sodium had been discharged from the cells. If the change in serum bicarbonate is necessarily related to transfers of either of these cellular cations, this temporal sequence suggests that it is to the exit of sodium from the cell rather than to the entry of potassium. Such a time lag between the two transfers has been noted in experimental animals by Conway and Hingerty (41). Had the other patients in our series been "saturated" and studied for a longer period of time, reciprocal movements of cellular sodium might have been observed more frequently.

Administration of large quantities of sodium without concomitant use of potassium has also been said to predispose to potassium depletion (42). In four of the patients the intake of sodium, prior to potassium therapy, was low. In none of the cases was depletion of cellular potassium consistently correlated with changes in the concentration of extracellular sodium. It is difficult, therefore, to assess the specific role of sodium therapy, or that of alkalosis, in the cases presented, but certainly deficit of potassium can occur in the absence of either.

Within the limits of the relatively large error of the calculation, a reciprocal relationship between changes in cell sodium and cell potassium was found only occasionally in our studies. Such a relationship appeared to be present in some instances. These results are in agreement with those of Darrow who demonstrated a reciprocal relationship in only three of the six infants with diarrhea whom he treated with potassium (10), and with previous studies in this department (16).

Clinical implications. The subjects of this investigation were probably representative of a large group of patients seen in ordinary hospital practice. All of the patients were maintained on parenteral fluids and were unable to eat. In addition most of them had lost gastrointestinal fluids to some degree. The incidence of unrecognized deficiency of potassium in such patients must be very great.

The diagnosis of potassium deficiency is not simple, as specific signs and symptoms are probably the exception rather than the rule. The diagnosis depends chiefly on recognition of the conditions under which it may develop. The most important of these appears to be a low potassium intake in association with normal renal function. An abnormally low concentration of potassium in serum is strongly suggestive of cellular deficit; a normal or high serum concentration does not ex- 
clude it. The most practical proof of the diagnosis at present is demonstration of cellular retention of administered potassium. Other methods include chemical analyses of tissue and possible measurement of total exchangeable potassium by means of the radioactive isotope, $\mathrm{K}^{42}$ (43).

Complete elaboration of the contraindications to potassium therapy awaits more extensive clinical experience. In the meantime it is certain that the most important contraindication is inadequate renal function due to any cause (35). Oliguria or anuria caused by intrinsic disease or extrinsic factors are absolute contraindications. As patients who are likely to have potassium deficiency are also likely to be suffering from peripheral vascular collapse, due at least in part to dehydration and sodium depletion, potassium therapy should be deferred until appropriate treatment for these conditions has been instituted. Adrenal cortical insufficiency is a contraindication unless this condition is overtreated with desoxycorticosterone or cortical extract. The limited experience with potassium therapy in patients with organic cardiac disease and associated potassium deficit, permits no comment concerning possible cardiac contraindications (44).

It is not known whether an excessive amount of potassium in the intracellular fluid is deleterious to the organism. But accummulation of potassium in the extracellular fluid is dangerous if it results in an elevation of concentration. The cardiotoxic effects of such an elevation are well known (45 to 49), and may be fatal; other possible toxic effects are less well understood (46). A high concentration of potassium in serum, therefore, contraindicates potassium therapy even though the cells may be depleted of the ion. Evidence has been advanced of increased hazard of potassium administration under certain circumstances when the concentration of serum calcium is low (50).

No arbitrary parenteral dose of potassium can be prescribed. Darrow has esimated that 3.5 m.eq. per kilogram per day of potassium can be administered safely in a period exceeding four to eight hours (51). The subjects of this study received up to 3.7 m.eq. per kilogram per day. The rate of intravenous infusion of the potassium was carefuly controlled and not allowed to exceed 20 m.eq. per hour. The concentration of the potassium in the infusion fluids was as high as $70 \mathrm{~m}$.eq. per liter, a concentration which is double that rec- ommended by Darrow (51). Under these conditions no untoward effects were observed.

No evidence is offered in our data that correction of a deficit of cellular potassium directly benefits the patient. Our patients belonged to no homogenous clinical state with a known case fatality rate or a predictable prognosis. On the other hand, the rationale of replacement therapy has been to restore the patient to a normal chemical state. It appears reasonable, therefore, to attempt to put the replacement of intracellular electrolytes on the same successful basis as that which has been achieved for the constituents of the extracellular fluid.

\section{SUM MARY}

Potassium was administered in daily doses of 0.7 to 3.7 m.eq. per kilogram to six adult patients maintained on parenteral fluids. Three normal subjects on isocaloric diets were given $4.4,3.2$, and 0 m.eq. of potassium per kilogram, as controls. The daily exchanges of electrolytes and nitrogen were measured.

In four of the patients the concentrations of potassium in serum were abnormally low. All of the patients retained administered potassium in the cellular phase in excess of nitrogen in amounts varying from 1.2 to 4.6 m.eq. per kilogram. Only one patient received potassium long enough to show that a maximum degree of retention had been reached. Each of the normal subjects who received potassium retained only 0.1 m.eq. per kilogram.

During periods of low potassium intake more potassium was lost in urine than in gastrointestinal fluid. In four patients during such periods the quantity in urine was greater than was the quantity during periods when the intakes were high and concentrations in serum were normal. The minimum amounts in urine in three of the patients deprived of exogenous potassium and maintained in nitrogen equilibrium, were 28,27 and 6 m.eq. per day, and in the normal subject 34 m.eq. per day. The potassium $U / P$ ratio was never less than 1.0.

\section{CONCLUSIONS}

1. Adult patients deprived of potassium by gastrointestinal disorders retain significant amounts of potassium when administered. 
2. Retention of potassium probably indicates cellular deficit of the ion.

3. Such deficits are frequently but not always associated with abnormally low concentrations of potassium in serum.

4. During administration of potassium to such patients the excretion of potassium tends to decrease rather than to increase.

5. The kidney in normal subjects as well as in depleted patients, under conditions of maximal need for conservation, has a limited minimal rate of excretion of the ion. This continued excretion by the kidney is an important factor in producing a state of potassium deficiency.

\section{BIBLIOGRAPHY}

1. Darrow, D. C., Medical progress; body-fluid physiology; relation of tissue composition to problems of water and electrolyte balance. New England J. Med., 1945, 233, 91.

2. Heppel, L. A., Electrolytes of muscle and liver in potassium-depleted rats. Am. J. Physiol., 1939, $127,385$.

3. Miller, H. C., and Darrow, D. C., Relation of serum and muscle electrolyte, particularly potassium, to voluntary exercise. Am. J. Physiol., 1941, 132, 801.

4. Thorn, G. W., and Firor, W. M., Desoxycorticosterone acetate therapy in Addison's disease; clinical considerations. J. A. M. A., 1940, 114, 2517.

5. Talbott, J. H., Periodic paralysis. A clinical syndrome. Medicine, 1941, 20, 85.

6. Danowski, T. S., Elkinton, J. R., Burrows, B. A., and Winkler, A. W., Exchanges of sodium and potassium in familial periodic paralysis. J. Clin. Invest., 1948, 27, 65.

7. Holler, J. W., Potassium deficiency occurring during treatment of diabetic acidosis. J. A. M. A., 1946, $131,1186$.

8. Danowski, T. S., Hald, P. M., and Peters, J. P., Sodium, potassium, and phosphates in the cells and serum of blood in diabetic acidosis. Am. J. Physiol., 1947, 149, 667.

9. Falconer, M. A., Osterberg, A. E., and Bargen, J. A., Intestinal obstruction in man; alterations in serum bases and their significance. Arch. Surg., 1939, 38, 869.

10. Darrow, D. C., The retention of electrolyte during recovery from severe dehydration due to diarrhea. J. Pediat., 1946, 28, 515.

11. Atchley, D. W., Loeb, R. F., Richards, D. W., Jr., Benedict, E. M., and Driscoll, M. E., On diabetic acidosis; a detailed study of electrolyte balances following the withdrawal and reestablishment of insulin therapy. J. Clin. Invest., 1933, 12, 297.
12. Harrison, H. E., Harrison, H. C., Tompsett, R. R., and Barr, D, P., Potassium deficiency in a case of lymphosarcoma with the sprue syndrome. Am. J. Med., 1947, 2, 131.

13. Govan, C. D., Jr., and Darrow, D. C., The use of potassium chloride in the treatment of the dehydration of diarrhea in infants. J. Pediat., 1946, 28, 541.

14. Elkinton, J. R., Winkler, A. W., and Danowski, T. S., Transfers of cell sodium and potassium in experimental and clinical conditions. J. Clin. Invest., 1948, $27,74$.

15. Hald, P. M., The flame photometer for the measurement of sodium and potassium in biological materials. J. Biol. Chem., 1947, 167, 499.

16. Elkinton, J. R., and Winkler, A. W., Transfers of intracellular potassium in experimental dehydration. J. Clin. Invest., 1944, 23, 93.

17. Sherman, H. C., Chemistry of Food and Nutrition. The Macmillan Company, New York, 1941.

18. Stewart, H. J., Smith, J. J., and Milhorat, A. T., Electrocardiographic and serum potassium changes in familial periodic paralysis. Am. J. M. Sc., 1940, 199, 789.

19. Stoll, B., and Nisnewitz, S., Electrocardiographic studies in a case of periodic paralysis. Arch. Int. Med., 1941, 67, 755.

20. Nicholson, W. M., and Branning, W. S., Potassium deficiency in diabetic acidosis. J. A. M. A., 1947, 134, 1292.

21. Frenkel, M., Groen, J., and Willebrands, A. F., Low serum potassium level during recovery from diabetic coma with special reference to its cardiovascular manifestations. Arch. Int. Med., 1947, 80, 728.

22. Keutmann, E. H., Bassett, S. H., and Warren, S. L., Electrolyte balances during artificial fever with special reference to loss through skin. J. Clin. Invest., 1939, 18, 239.

23. Benedict, F. G., A study of prolonged fasting. Carnegie Institution, Publication No. 203, Washington, D. C., 1915.

24. Howard, J. E., Bigham, R. S., Eisenberg, H., Wagner, D., and Bailey, E., Studies on convalescence; nitrogen and mineral balances during starvation and graduated feeding in healthy young males at bed rest. Bull. Johns Hopkins Hosp., 1946, 78, 282.

25. Reifenstein, E. C., Jr., Effect of negative nitrogen balance on the phosphorus, calcium, and potassium balances of a normal individual. Conference on Metabolic Aspects of Convalescence, 1944, 8, 64, Josiah Macy Jr. Foundation.

26. McCance, R. A., Experimental sodium chloride deficiency in man. Proc. Roy. Soc. Med., London, 1936, 119, 245.

27. Winkler, A. W., Hoff, H. E., and Smith, P. K., The toxicity of orally administered potassium salts in renal insufficiency. J. Clin. Invest., 1941, 20, 119. 
28. Wolf, A. V., Renal regulation of water and some electrolytes in man, with special reference to their relative retention and excretion. Am. J. Physiol., 1947, 148, 54.

29. Wiley, F. H., Wiley, L. L., and Waller, D. S., Effect of ingestion of sodium, potassium, and ammonium chlorides and sodium bicarbonate on metabolism of inorganic salts and water. J. Biol. Chem., 1933, 101, 73.

30. MacKay, E. M., and Butler, A. M., Studies of sodium and potassium metabolism; effect of potassium on sodium and water balances in normal subjects and patients with Bright's disease. J. Clin. Invest., 1935, 14, 923.

31. Borst, J. G. G., The cause of hyperchloremia and hyperazotemia in patients with recurrent massive hemorrhage from peptic ulcer. Acta med. Scandinav., 1938, 97, 68.

32. Howard, J. E., and Mason, R. E., Metabolic studies before and after operation of chronically-ill patients fed entirely by vein. Conference on Metabolic Aspects of Convalescence, 1946, 13, 143, Josiah Macy Jr. Foundation.

33. Coller, F. A., Iob, V., Vaughan, H. H., Kalder, N. B., and Moyer, C. A., Translocation of fluid produced by the intravenous administration of isotonic salt solutions in man post-operatively. Ann. Surg., 1945, 122, 663.

34. Albright, F., Reifenstein, E. C., Jr., and Forbes, A. P., Does potassium move with nitrogen? Conference on Metabolic Aspects of Convalescence, 1945, 11, 25, Josiah Macy Jr. Foundation.

35. Elkinton, J. R., Tarail, R., and Peters, J. P., Transfers of potassium in renal insufficiency. Unpublished.

36. Winkler, A. W., and Smith, P. K., Renal excretion of potassium salts. Am. J. Physiol., 1942, 138, 94.

37. Smith, H. W., The Physiology of the Kidney. Oxford University Press, New York, 1937.

38. Stewart, J. D., and Rourke, G. M., The effects of large intravenous infusions on body fluid. J. Clin. Invest., 1942, 21, 197.

39. Goodyer, A. V. N., Peterson, E. R., and Relman, A. S., Unpublished observations.

40. Darrow, D. C., Schwartz, R., Iannucci, J. F., and Coville, F., The relation of serum bicarbonate concentration to muscle composition. J. Clin. Invest., 1948, 27, 198.

41. Conway, E. J., and Hingerty, D., Relations between potassium and sodium levels in mammalian muscle and blood plasma. Biochem. Journ., 1948, 42, 372.

42. Wallace, W. M., The balance of sodium and potassium in repair solutions. J. Clin. Invest. (Proc.), 1948, 27, 560.

43. Moore, F. D., The use of isotopes in surgical research. Surg., Gyn. \& Obs., 1948, 86, 129.

44. Thomson, W. A. R., The effect of potassium on the heart in man. Brit. Heart J., 1939, 1, 269.

45. Hoff, H. E., Smith, P. K., and Winkler, A. W., The cause of death in experimental anuria. J. Clin. Invest., 1941, 20, 607.

46. Finch, C. A., Sawyer, C. G., and Flynn, J. M., Clinical syndrome of potassium intoxication. Am. J. Med., 1946, 1, 337.

47. Keith, N. M., Burchell, H. B., and Baggenstoss, A. H., Electrocardiographic changes in uremia associated with high concentration of serum potassium. Am. Heart J., 1944, $27,817$.

48. Tarail, R., Electrocardiographic abnormalities in a case of uremia manifesting hyperpotassemia. Am. Heart J., 1948, 35, 665.

49. Tarail, $R$., The relation of abnormalities in concentration of serum potassium to electrocardiographic disturbances. Am. J. Med., in press.

50. Engel, F. L., and Martin, S. P., Hypokaliemia masking the symptoms of hypocalcemia. Am. J. Med. (Proc.), 1948, 4, 455.

51. Darrow, D. C., Disturbances in electrolyte metabolism and their management. Bull. N. Y. Acad. Med., 1948, 24, 147. 